\title{
NOTE ON LEAD POISONING BY CARBONATED BEVERAGES.
}

\section{By Durand Woodman.}

In the Summer months of last year (1888) there was an unusual number of cases of lead poisoning in the hospitals of Newark, $\mathrm{N}$. J., the greater part of which were unaccountable, so far as occupation of those suffering was concerned.

In several cases suspicion was strongly directed to bottled beer, soda water and other bottled carbonated beverages, and attention was particularly directed to the patent combination rubber and metal stopper, consisting of a rubber washer held in place by a metal disc.

Qualitative examination proved this disc to be an alloy of lead and tin. Evidences of corrosion were also visible, a gray crust of greater or less depth, according to length of time the stopper had been in use, indicating action of the carbonated liquid on the alloy. Analysis of the alloy gave

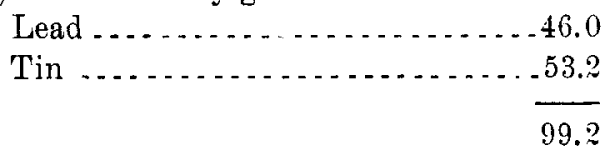

which corresponds closely with the composition of common solder.

Dr. Herold, of Newark, in a report to the Board of Health, stated that he found two grades of stoppers, one containing lead, 42.4 per cent., practically corresponding to the above analysis, and another containing 83.6 per cent lead, corresponding to common pewter.

In unconcentrated samples of sarsaparilla heer, ginger ale and soda water, when not too highly colored, hydrogen sulphide produced a reaction varying from a mere darkening of the fluid to a distinct precipitate.

The quantities of lead, and in some cases also, of tin, were determined in several samples by evaporating ignitıng to ash, treating with nitric acid and evaporating, to insure conversion of tin to oxide, then taking up by dilute hydrochloric acid, precipi- 
tating by hydrogen sulphile and determining as sulphate in the usual manner.

The quantities found are given in the following tabular statement :

\begin{tabular}{|c|c|c|c|c|c|c|}
\hline \multirow[b]{2}{*}{ No. } & & \multirow[b]{2}{*}{ Brand. } & \multirow[b]{2}{*}{ Quantity used. } & LEAD. & \multicolumn{2}{|c|}{$\begin{array}{l}\text { GRAINS PER } \\
\text { GALION. }\end{array}$} \\
\hline & & & & Milligrams found. & Lead. & Tin. \\
\hline 437 & Sola Water. & IC V & $250 \mathrm{c.c}$ & 3. & 0.63 & \\
\hline 438 & $" \quad "$ & & $250 \mathrm{ccc}$ & 2. & 0.46 & 1.4 \\
\hline 439 & Ginger Ale. & CS & and & 47 & & $\cdots$ \\
\hline 440 & Sodia Water, & OB & 675 c. & 3.7 & 0.39 & \\
\hline $44^{3}$ & 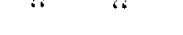 & VSMH & $1800 \therefore c$ & 47.0 & $1, \overline{2}$ & 1.63 \\
\hline
\end{tabular}

The last sample, No. 442 , was a mixture of several different brands, and the bottles were kept at week lying on their sides before opening them.

It will be observed that more tin has been dissolved than lead. Proust is authority for the statement that from an alloy of lead 75 , tin 25, vinegar dissolves tin only. (Watts III., 535.) A small amount of copper, not determined, was also found in No. 4t:, probably from some vessel or pipe at the bottling estaulishments.

In considering these figures, it is to be taken into account that ordinary bottled soda water is flavored with lemon, perhaps rein: forced by citric acid, which would be another factor in the solvent action duc to the carbonated liquid.

In experiments made with carbonated water alone, Dr. Herold reported finding 0.52 grain of lead per gallon after only two days' contact with the stopper's, under the same conditions of pressure.

Of a number of samples recently examinea from bottles closed by ordinary corks, several have responded slightly to hydrogen sulphide, indicating, as above mentioned, that a part of the dissolved metals has its source in the vessels and transfer pipes at the bottling establishment.

The general result of the attention called to the subject has been, however, a marked improvement, due to the substitutiou of ordinary corks and rubber stoppers by the leading manufacturers. 